Supplement of Hydrol. Earth Syst. Sci., 21, 4479-4493, 2017

https://doi.org/10.5194/hess-21-4479-2017-supplement

(c) Author(s) 2017. This work is distributed under

the Creative Commons Attribution 3.0 License.

(c) (1)

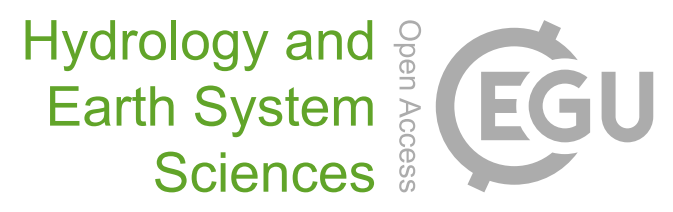

Supplement of

\title{
Monitoring and modeling infiltration-recharge dynamics of managed aquifer recharge with desalinated seawater
}

Yonatan Ganot et al.

Correspondence to: Yonatan Ganot (yonatan.ganot@mail.huji.ac.il)

The copyright of individual parts of the supplement might differ from the CC BY 3.0 License. 


\section{S1 Testing the numerical model with different pedotransfer functions (PTF)}

The numerical model was also tested with two different USDA textural-classes PTF (Carsel and Parrish, 1988; Tóth et al., 2015). The neural-network PTF (ROSETTA, Schaap et al., 2001) that is presented in the paper (Table 1) is based on particlesize class (sand, silt and clay) and bulk density. This PTF resulted in 8 materials (sediments) each with a different hydraulic

5 function that was used in the 10-layers model (Fig. 2c). However, the USDA textural-classes PTF reduces the number of materials to 3 (Carsel and Parrish, 1988) and 4 (Tóth et al., 2015) as presented in Tables S1 and S2, respectively. The results of the numerical simulations with the different PTF, including the calibrated and uncalibrated results of the PTF obtained with ROSETTA, are shown in Fig. S1. Among the uncalibrated PTF that were tested, the PTF of Tóth et al. (2015) was closest to the calibrated simulation results.

10

Table S1. The van-Genuchten-Mualem hydraulic functions parameters obtained by the PTF of Carsel and Parrish (1988).

\begin{tabular}{ccccccc}
\hline Model layers & Soil texture & $\theta_{\mathrm{r}}$ & $\theta_{\mathrm{s}}$ & $\alpha\left(\mathrm{m}^{-1}\right)$ & $\mathrm{n}$ & $K_{s}\left(\mathrm{~m} \mathrm{~d}^{-1}\right)$ \\
\hline $1,4,5,8,10$ & Sand/Kurkar & 0.045 & 0.43 & 14.5 & 2.68 & 7.13 \\
$2,3,6$ & Sandy clay loam & 0.1 & 0.39 & 5.9 & 1.48 & 0.31 \\
7,9 & Sandy loam & 0.065 & 0.41 & 7.5 & 1.89 & 1.06 \\
\hline
\end{tabular}

Table S2. The van-Genuchten-Mualem hydraulic functions parameters obtained by the PTF of Tóth et al. (2015).

\begin{tabular}{ccccccc}
\hline Model layers & Soil texture & $\theta_{\mathrm{r}}$ & $\theta_{\mathrm{s}}$ & $\alpha\left(\mathrm{m}^{-1}\right)$ & $\mathrm{n}$ & $K_{s}\left(\mathrm{~m} \mathrm{~d}^{-1}\right)$ \\
\hline 1 & Sand & 0.061 & 0.411 & 2.58 & 1.80 & 7.08 \\
$2,3,6$ & Sandy clay loam & 0.037 & 0.384 & 7.17 & 1.12 & 0.32 \\
$4,5,8,10$ & Sand/Kurkar & 0.034 & 0.368 & 3.56 & 1.78 & 1.59 \\
7,9 & Sandy loam & 0.037 & 0.437 & 6.81 & 1.2 & 1.59 \\
\hline
\end{tabular}



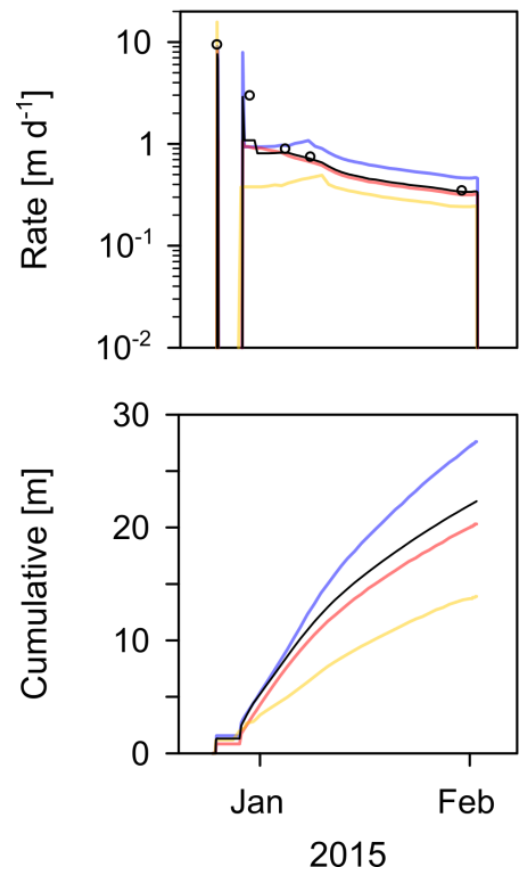

\section{Recharge}
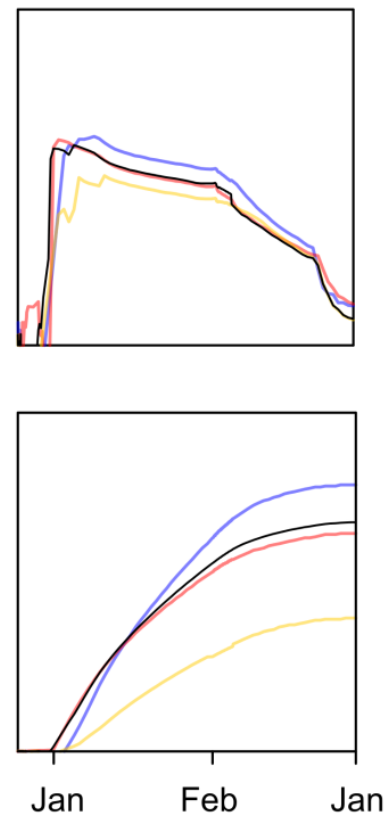

2015

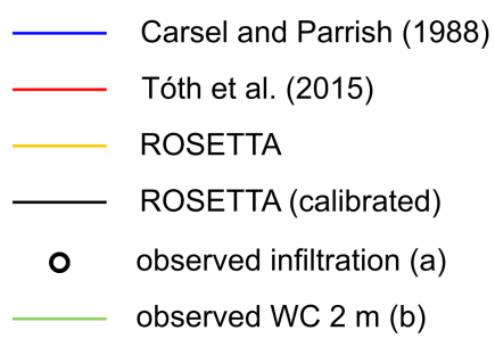

(b)

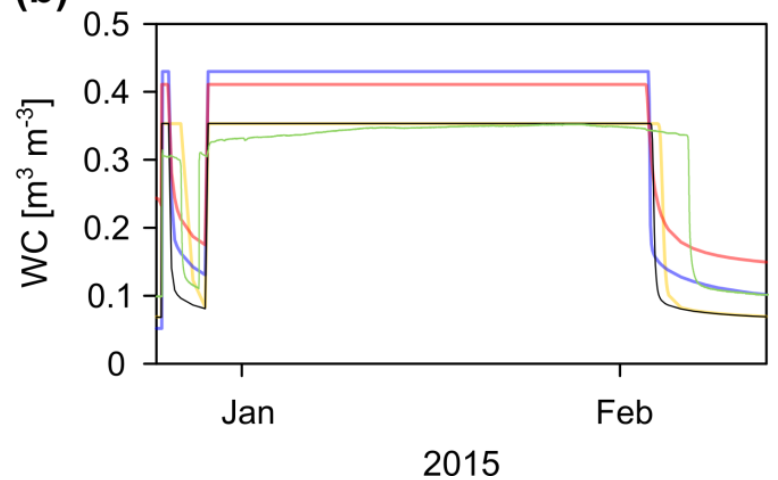

Figure S1. Numerical model simulations with different pedotransfer functions. (a) Infiltration and recharge rates (top); cumulative infiltration and recharge (bottom). (b) Volumetric water content (WC) at depth of 2 m.

\section{S2 Preliminary falling-head unsaturated column experiment}

5 Column experiment with desalinated seawater was conducted to identify the main soil-water processes at the top sand layer of the infiltration pond, focusing on changes in infiltration rates to physical clogging and chemical dissolution/precipitation (assuming negligible effect of biological processes). A Plexiglas column $(100 \times 10 \mathrm{~cm}$, length $\mathrm{x}$ diameter) was packed with sand (silt + clay < 1\%) from the Menashe site. The lower part of the column (0 to $40 \mathrm{~cm})$ was dry-packed with four layers of sand (each $10 \mathrm{~cm}$ layer represent the layers identified in the field), and covered with aluminum foil to prevent biofilm

10 growth. The upper part of the column was used as a water tank (Fig. S2a).

Water levels were monitored continuously by a pressure transducer (Freescale MPX2010DP), showing decreasing infiltration rates after each successive run, implying sediment clogging (Fig. S2b). At the end of the experiment ( 45 pore volume) an infiltration rate decrease by a factor of $\sim 1.5$ was observed. No evidence of suspended solids was found in the output filtered water $(0.45 \mu \mathrm{m})$, which implies negligible transport of micro-particles. This is expected as $98 \%$ of the

15 sediment particles have a diameter larger than $106 \mu \mathrm{m}$. However, it is noted that transport and rearrangements of particles within the column could lead to physical clogging.

Chemical analysis (cations: ICP, Spectro Arcos; anions: IC, Dionex ICS 3000) showed that ion exchange of calcium replacing sodium was the main geochemical process taking place $\left(\mathrm{Na}_{2} \mathrm{X}+\mathrm{Ca}^{2+} \rightarrow \mathrm{CaX}+2 \mathrm{Na}^{+}\right.$; where $\mathrm{X}$ is the exchange 
site), while no evident for carbonate dissolution was found (measured as $\left[\mathrm{HCO}_{3}{ }^{-}\right]$by titration; Fig. S2c). This, together with observations of a continuous decrease in infiltration rate after the sediments reached chemical equilibrium with the inlet desalinated seawater ( $\sim 15$ pore volume), suggests that physical clogging due to compaction or grain rearrangement is the main clogging process. Nevertheless, the effect of this clogging is minor, and the final infiltration rates are still very high

$5\left(\sim 15 \mathrm{~m} \mathrm{~d}^{-1}\right)$ in comparison to the final field-infiltration-rates measured in full-scale operative MAR events described in the text $\left(0.4 \mathrm{~m} \mathrm{~d}^{-1}\right)$.

(a)

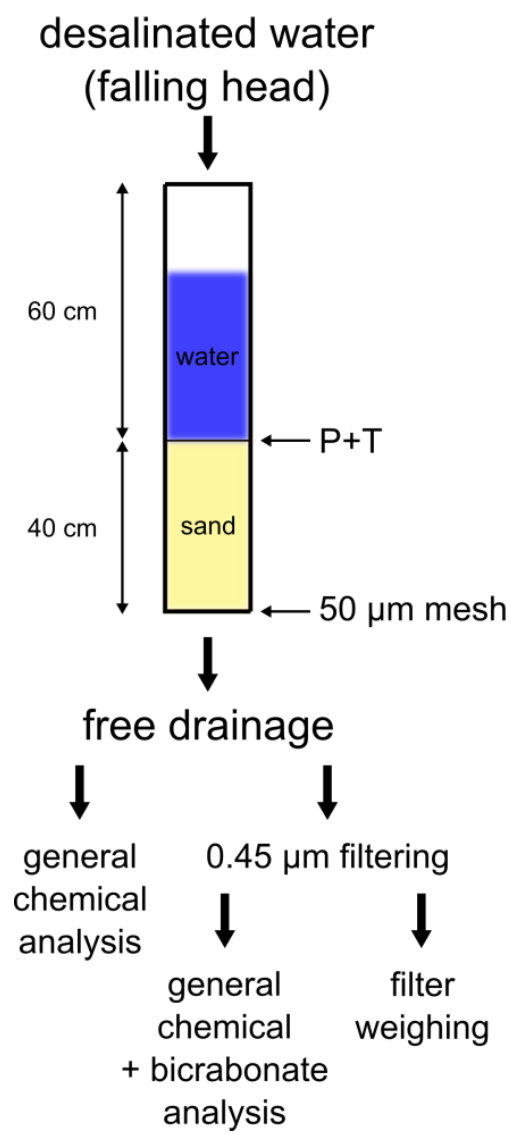

(b)

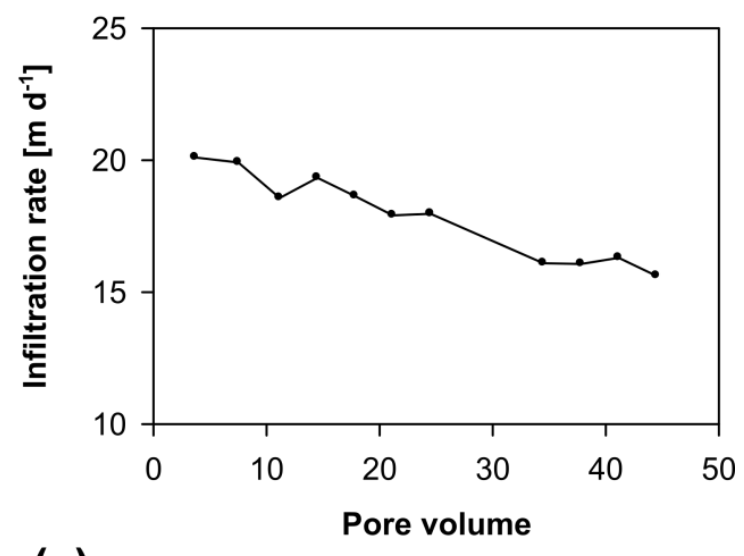

(c)

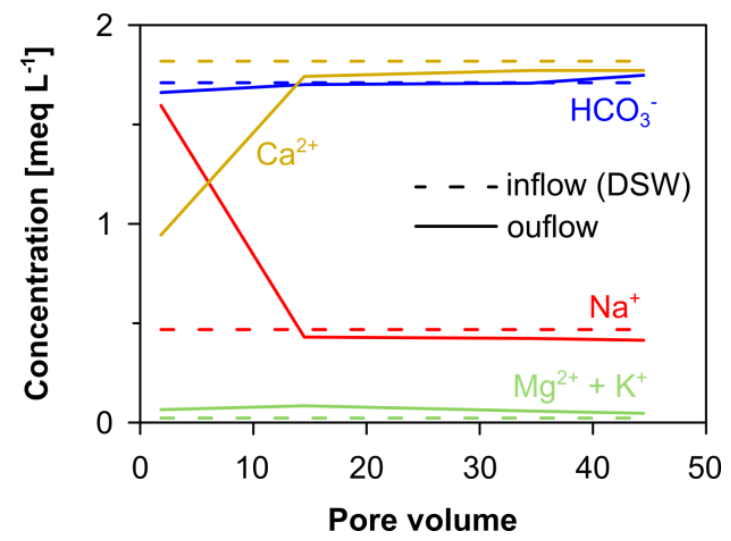

Figure S2. Preliminary column experiments with desalinated seawater. (a) Column experiment setup. (b) Average infiltration rates. (c) Major cations and bicarbonate concentration. 